\title{
A Comparative Study of Interjections in Chinese and English
}

\author{
Anmin Mao \\ School of Foreign Studies, Yangtze University, Jingzhou, China \\ Email:mamiemao@qq.com
}

How to cite this paper: Mao, A. M. (2020). A Comparative Study of Interjections in Chinese and English. Open Journal of Modern Linguistics, 10, 315-320.

https://doi.org/10.4236/ojml.2020.104018

Received: July 11, 2020

Accepted: August 11, 2020

Published: August 14, 2020

Copyright () 2020 by author(s) and Scientific Research Publishing Inc. This work is licensed under the Creative Commons Attribution International License (CC BY 4.0).

http://creativecommons.org/licenses/by/4.0/

\begin{abstract}
Interjections are emotive words with no referential content. In both Chinese and English, they are classified as a special word class. In order to better comprehend interjections and further deepen our knowledge of these two language systems, a comparison of Chinese interjections and English interjections is made at three levels-morphological structures, semantic relations and syntactic functions. Similarities of Chinese and English interjections are found to outnumber their differences.
\end{abstract}

\section{Keywords}

Interjections, Comparison, Morphological Structure, Sense Relation, Syntactic Function

\section{Introduction}

Interjection is a word or phrase used to express emotions (often surprise, shock, pain etc.). In general, interjections in Chinese and English are characterized as follows: 1) Interjections come in many forms. They may be a single word or consist of more than one word, and some content words can be converted into interjections as well. 2) Interjections are emotive words with no referential content. They are highly context-dependent. 3) Interjections in most cases appear alone at the head of a sentence. They function independently without any grammatical relations to any other syntactical components (Guo, 2004).

In both Chinese and English, interjections share the above features. Yet, in present grammatical study, there is still controversy over which word class those interjections should be divided into. Some grammarians put interjection into the category of content word and name it "special nominal word" due to its own 
features (Huang \& Liao, 2002). Some define interjection as functional word (Huang, 1989; Zhang, 2000), and a few content words can be converted into interjections (Bo \& He, 2004). Others argue that interjection should be counted out of the traditional nominal and form word but be classified as another special word class (Zhang, 2002). Still others in earlier days deem interjection simply as part of onomatopoeia (Ren, 1981).

As a special word class, interjections in Chinese and English have much in common, but there are some subtle differences as well. This article focuses on the comparisons of Chinese and English interjections mainly at three levels-morphological structures, semantic relations and syntactic functions-in the hope of getting a better comprehension of interjections and deepening the knowledge of these two language systems.

\section{Morphological Structure of Interjections in Chinese and English}

In general, three kinds of structures are applied to Chinese interjections as well as English interjections: mono-word structure, double-word structure and triple-word structure.

\subsection{Mono-Word Structure}

Interjections of this type constitute most of Chinese and English interjections. They are most frequently used. Examples in Chinese are “啊, 嗳, 吆, 喂” and so forth. In English, there are "ah, oh, ow, whew, uh" ect.

Noticeably, in Chinese, all the mono-word structural interjections are also mono-syllabic (one of the features of Chinese characters). However, in English, besides these mono-syllabic words as examples illustrated above, there are many other polysyllabic words, or rather, double-syllabic words e.g. hurray, alas, ahem, hiya, okey, ahoy.

\subsection{Double-Word Structure}

In Chinese, interjections of this structure mainly come in two forms: 1) interjections are composed of two mono-word interjections e.g. 哎 + 哟 $\rightarrow$ 䒝哟; 噢 + 吆 $\rightarrow$ 噢吆; 哎 + 呀 $\rightarrow$ 哎呀; 2) interjections are just repetition of one mono-word interjection e.g. 哈哈, 嘿嘿, 呵呵. In the latter case, grammarians sometimes regard them as onomatopoeia words, as defined in Xinhua Dictionary (1998).

These two forms also fit English interjections.

Form 1: huh + uh $\rightarrow$ huh-uh (= no), uh + huh $\rightarrow$ un-huh (=yes), uh + oh $\rightarrow$ uh oh

Form 2: ha $\rightarrow$ ha ha; ho $\rightarrow$ ho ho

Besides, the combination of one non-interjection (without content meaning if used alone) plus one mono-word interjection may also turn into an interjection e.g. heigh + ho $\rightarrow$ heigh-ho. 
One more thing to mention is that the above classification concerning English interjections is based on the supposition that no interjections are considered as one word in case of compound word with or without hyphen between.

Moreover, "bye bye", as a kind of greetings in English, is also defined as "interjection" in Oxford Advanced Learner's English-Chinese Dictionary (Hornby, 2004), so "bye bye" falls into this category as well.

\subsection{Triple-Word Structure}

In Chinese, such structure is realized by repetition of the latter word of a double-word interjection in the first form e.g. 䒝哟 + 哟 $\rightarrow$ 哎哟哟; 哎呀 + 呀 $\rightarrow$ 䒝呀呀.

In English, examples are limited: "ooh la la", "ho ho ho", "oops-a-daisy".

\section{Sense Relations of Interjections in Chinese and English}

In the above discussion, interjections are considered as independent linguistic units. Further, these lexemes are related in one way or another. According to their relations among meaning, sound and spelling, interjections can be classified as follows and in this way, similarities and differences of interjections in Chinese and English are discussed.

\subsection{Identical in Sound and Spelling, Different in Meaning}

According to the definition and classifications of homonyms by Lin Chengzhang and Liu Shiping (2005) in An Introduction to English Lexicology, interjections in this category are actually perfect homonyms. Such interjections are found to be in both Chinese and English.

In Chinese, “烸” (hāi) has different senses:

e.g. 烸, 我怎么这么糊涂! (to show one's regret)

烸, 到这边来! (to call one's attention or greet somebody)

Besides, there are many other examples like “啊 (à)" (to show admiration; to make a promise), “嘿 (hēi)" (to show admiration; to remind sb. of sth.) and so on.

In English, some frequently used interjections are with various senses as well. "Ah, oh, well, why" etc. are typical instances. Take "oh" for example:

e.g. "Oh no!" she cried. (scary)

Oh, it is here, behind the door. (surprise and happiness)

Oh, please don't ask me any more. (plea, or dissatisfaction)

The above illustrations do not count in the differing in parts of speech.

In English, many interjections are converted from content words, and they are typical instances of interjections with identical sound-form but different parts of speech and meaning, for example, "well" (interj., n., a., ad. \& v), "why" (interj. \& ad.), "come" (interj. \& verb), "look/say/shoot" (interj., v. \& n.), "dear" (interj., a.) etc. In addition to these converted interjections, several other interjections themselves can be converted into words of other parts of speech. They fit in this 
case as well. For example, "wow" can be interjection, noun and verb. "Hallo" can serve as both interjection and nouns.

In Chinese, the number of interjections converted from content words in much smaller than that in English. Still, “喂 (wèi)” (intej. \& verb.) and “吓” (hè) (interj. \& verb) are two examples. Other non-converted interjections seldom function as other parts of speech.

e.g. 喂, 快来呀! (interj.-to greet or call one's attention)

母亲正在喂孩子吃饭. (v.—to feed sb, put food in one's mouth)

那位农妇正在喂鸡. (v.-to cultivate an animal)

吓, 怎么能这样呢! (interj.—to show discontentment)

劫匪恐吓车上的乘客. (v.-to scare, frighten)

\subsection{Identical in Meaning, Different in Sound and Spelling}

It is common to notice that one emotion can be expressed by more than one interjections, which are synonyms from the angle of semantic relations.

Both in Chinese and English, there are plenty of such synonymic interjections.

In Chinese, to show that somebody suddenly understands or realizes something, “哦 (ò), 噢 (ō)” are alike; to show one’s confusion, “啊 (ă), 咦（yí), 哦 (ó)" are changeable in some situations.

e.g. 哦, 我明白了. 噢, 我懂了.

啊, 你说什么? 哦, 是这样吗? 咦, 怎么是你?

In English, "hello, hi, hey, hiya, ho" are all used to greet somebody; "oh, ouch, ow, wow", are exclaimed when a sudden pain hurts somebody.

\subsection{Identical in Meaning and Sound, Different in Spelling}

This is another kind of synonymic interjection with different spelling but same sound.

In Chinese, there are “嘿 (hēi), 烸 (hēi)” with similar senses: 1) to greet somebody; 2) call one's attention; 3 ) to express surprise or admiration. “啊 (ā á ă à), 呵 (à á à à)" are other examples.

In English, forms may differ. In most cases, synonymic interjection is realized just by adding an " $h$ " at the end of a certain interjection, for example, "ah" and "ahh" [a]; ha and "hah" [ha]; "o" and "oh" [ou]. Moreover, "hurray" [hurei] and "hooray" [hurei] are another pair with the alteration from "ur" to "oo".

\subsection{Identical in Meaning and Spelling, Different in Sound}

Examples of such interjections in Chinese and English are similarly few.

In Chinese, 嚄 ( the same-to show one's surprise.

e.g. 嚄 (huō), 好大的水库!

嚄 (ŏ), 这是怎么搞的?

In English, to show one's dislike, one can say "ugh" $[\wedge \mathrm{g} ; \wedge \mathrm{k} ; \wedge \mathrm{h}]$. Besides, there are "ahem" [ə'hem; m'hm] showing one's sadness, shame or fear. 


\subsection{Identical in Spelling, Different in Sound and Meaning}

Almost no interjections in English have been found falling into this category (homographs), though the meaning of an interjection may change with various intonations. However, in Chinese, examples are relatively more, which is due to the changeable four tones.

For instance, the word “啊” and “嗳” have different senses with different sounds, or to be exact different tones.

e.g. 啊 (ā), 这花多美哇! (admiration)

啊 (á), 你说什么? (query)

啊 (ă), 这是什么回事? (confusion)

啊 (à, shorter), 好吧! (promise)

啊 (à, longer), 伟大的祖国! (admiration or high praise)

e.g. 嗳 (āi), 你们看, 谁来了! (to remind something)

嗳 (ăi), 别那么说. (disagreement)

嗳 (ài), 早知道这样, 我就不来了. (regret)

\section{Syntactic Functions of Interjections in Chinese and English}

Syntactic functions of interjections in China and English are similar.

As mentioned in the introduction, interjections appear alone in a sentence and they function independently without any grammatical relations to any other syntactical components (Guo, 2004). In most situations, they are punctuated in one of two ways, depending on how strong the emotion they are to express (Strumpf \& Douglas, 2004). If the interjection is mild, it can be included in a single sentence, separated from the rest syntactical components by a comma and in this way functions as "independent element", or rather, "exclamation". Strong interjections stand alone, punctuated with an exclamation mark, in which case interjections serve as "holophrase", or rather, a kind of "exclamatory sentence". In addition, some interjection plus an question mark or spoken with doubtful mood can also be used as interrogative sentence which is defined as "interjection question" (Xing, 2002).

e.g. 艾, 病了两个月, 把工作都耽搁了. (Independent element or exclamation)

㧵! 胡说八道! (Exclamatory sentence)

啊? 我不知道. 会不会请了假到医院看病去了? (Interjection question)

Oops, I hit the wrong button. (Independent element or exclamation)

Bravo! Encore! (Exclamatory sentence)

- I'm a technician.

- $\underline{\text { Oh}}$ I cannot tell from your appearance. (Interjection question)

\section{Conclusion}

As the earliest vocal form, interjection is a special word class and most of them are simply conventional. Through comparisons of Chinese and English interjec- 
tions, similarities are found outnumbering their differences. The reasons are worth noticing, which may partially due to its conventionality or the common emotions shared by all human beings. The research results lead to a more comprehensive understanding of interjections at such three levels as morphological structures, semantic relations and syntactic functions. Moreover, the comparison between Chinese interjections and English interjections can further deepen our knowledge of these two language systems.

Limitations of this article may lie in the lack of recognized lists of Chinese and English interjections. Some words may be defined as interjection in some dictionaries but fail to be so in others. Thus, it is quite possible to have some cases of interjections left out.

\section{Conflicts of Interest}

The author declares no conflicts of interest regarding the publication of this paper.

\section{References}

Bo, B., \& He, Z. A. (2004). A New English Grammar. Beijing: World Knowledge Press. (In Chinese)

Guo, R. (2004). A Study of Modern Chinese Parts of Speech. Beijing: Commercial Press. (In Chinese)

Hornby, A. S. (2004). Oxford Advanced Learner's English-Chinese Dictionary (6th ed.). Beijing: Commercial Press.

Huang, B. R., \& Liao, X. D. (2002). Modern Chinese (Revised 3rd ed.). Beijing: Higher Education Press. (In Chinese)

Huang, H. S. (1989). Modern Chinese Grammar and Rhetoric (Revised ed.). Beijing: Catalogs and Documentations Publishing House. (In Chinese)

Institute of Linguistics of Chinese Academy of Social Sciences (1998). Xinhua Dictionary (1998 Revised ed.). Beijing: Commercial Press. (In Chinese)

Lin, C. Z., \& Liu, S. P. (2005). An Introduction to English Lexicology (3rd ed.). Wuhan: Wuhan University Press.

Ren, X. L. (1981). A Comparative Grammar of Chinese-English. Beijing: China Social Sciences Press. (In Chinese)

Strumpf, M., \& Douglas, A. (2004). The Grammar Bible. Beijing: China Translation and Publishing Corporation.

Xing, F. Y. (2002). Modern Chinese Grammar and Rhetoric. Beijing: Higher Education Press. (In Chinese)

Zhang, D. Z. (2002). A Practical English Grammar. Beijing: Foreign Language Teaching and Research Press. (In Chinese)

Zhang, Y. S. (2000). Function Words in Modern Chinese. Shanghai: East China Normal University Press. (In Chinese) 